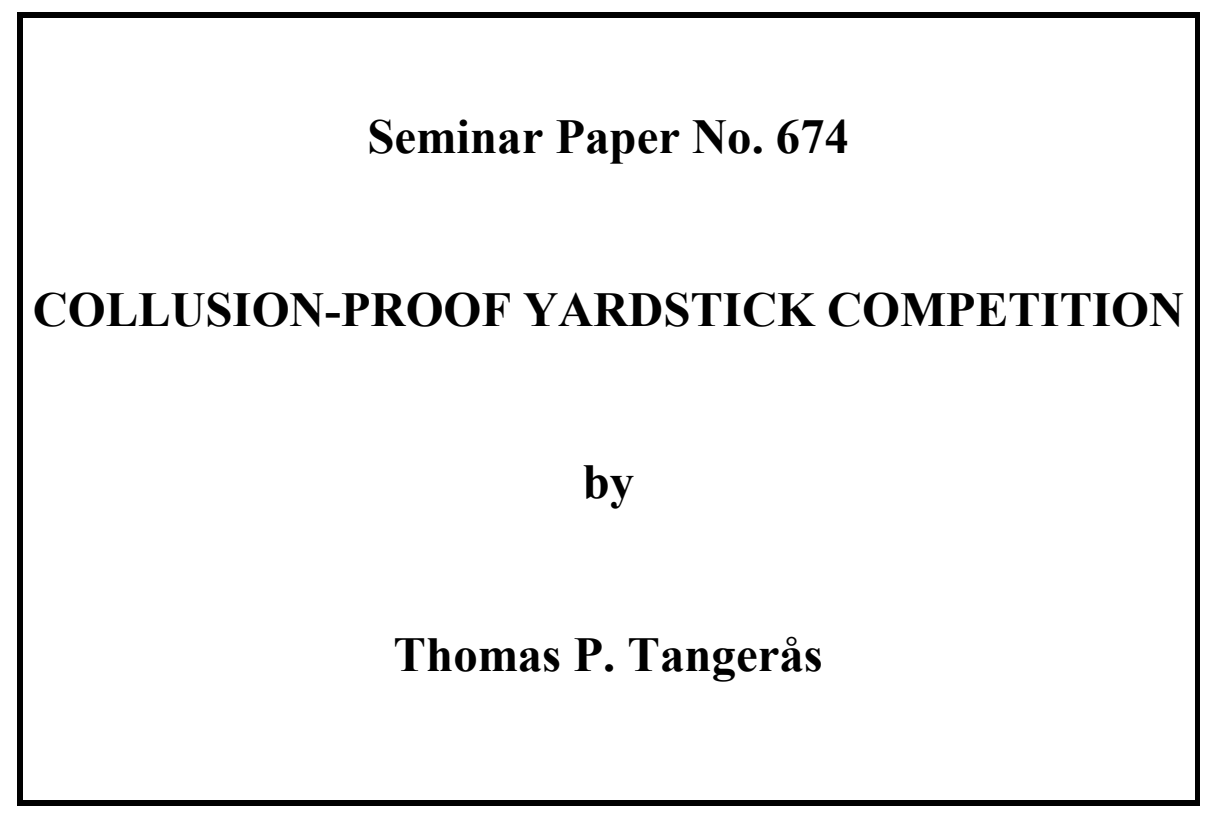

\author{
Thomas P. Tangerås
}

INSTITUTE FOR INTERNATIONAL ECONOMIC STUDIES Stockholm University 


\section{Seminar Paper No. 674 \\ COLLUSION-PROOF YARDSTICK COMPETITION}

by

Thomas P. Tangerås

Papers in the seminar series are also published on internet in Adobe Acrobat (PDF) format.

Download from http://www.iies.su.se/

Seminar Papers are preliminary material circulated to stimulate discussion and critical comment.

June 1999

Institute for International Economic Studies

S-106 91 Stockholm

Sweden 


\title{
Collusion-proof yardstick competition ${ }^{\infty}$
}

\author{
Thomas P. Tangeråsy \\ J une 23, 1999
}

\begin{abstract}
A bstract
This paper analyses the incentives for collusion when an industry is regulated by means of yardstick competition. The central assumption is that ..rms must write collusive side contracts before the revelation of private information and are unable to communicate later. It is shown that optimal collusion-proof regulation demands more high-powered (low-powered) incentives to high-productivity (low-productivity) ..rms than prescribed by the second-best contract. Collusion is costly to society also when correlation of private information is near perfect. This contrasts with the result by Laxont and Martimort (1998b), that the cost of collusion vanishes in the limit.
\end{abstract}

J EL Classi..cation: L51.

Keywords: Yardstick competition, collusion, regulation.

I thank Harry Flam, Bruno J ullien, Torsten Persson, J ohan Stennek and seminar participants in Bergen and Stockholm for their helpful comments. This research has been ..nanced by the $J$ an Wallander and Tom Hedelius R esearch Foundation.

y IIES. Address: Institute for International Economic Studies, Stockholm University, S-10691 Stockholm, Sweden. E-mail: thomas.tangeraas@iies.su.se 


\section{Introduction}

Regulated industries such as telecommunications, electricity distribution, water supply and health care consist of multiple ..rms. Costs typically covary across .rms since they produce under similar conditions. Correlation of costs gives the regulatory authority the possibility to establish industry standards against which to measure the performance of each individual ..rm. High (low) performance ..rms are rewarded (punished) accordingly. This is known as yardstick competition or relative performance evaluation and is a powerful tool to extract rents and increase production eф ciency. ${ }^{1}$

Due to its attractive features, Laxont and Tirole (1993) predict "an increased use of yardstick competition in segments of regulated industries such as water and electricity distribution" (p.86). Examples of current applications of yardstick competition include the UK water industry (Cowan, 1997), Norwegian electricity distribution (Dalen, Moen and Riis, 1998), the J apanese railway industry (M izutani, 1997) and the operation of Swedish motor-vehicle inspections (Y Ivinger, 1998). The best known example of yardstick competition is probably Medicare's reimbursement of hospital costs in the US, see Shleifer (1985) for a description. Although this paper focuses on the application to regulation, yardstick competition extends beyond performance comparisons of ..rms. Many labour contracts have elements of relative performance evaluation (Lazear, 1995), and Rappaport (1999) argues that manager compensation should be related to how the ..rm performs relative to a "peer index". It has been suggested that public agencies could be divided into subunits in order to facilitate eq ciency comparisons. The Review

\footnotetext{
${ }^{1}$ For example, the regulator is able to extract all surplus from ..rms and reach full et ciency if technologies are perfectly correlated. See Baiman and Demski (1982), Holmström (1982), Nalebux and Stiglitz (1983), Demski and Sappington (1984) for general treatments and Shleifer (1985), A uriol and Laxont (1992), Auriol (1993), Dalen (1998) and Sobel (1999) for applications to regulation.
} 
of Commonwealth/State Service Provision (RCSSP) in Australia publishes since 1995 performance indicators on a number of government services such as education, health and justice. One of the intentions is to "foster yardstick competition by promoting greater debate about comparative performance" (RCSSP, 1999, $p$. 5). Further, Yaisawarng and Puthucheary (1997) sketch how, within public agencies in New South Wales, resources could be allocated among dixerent operation units as a function of their relative eq ciency.

The problem with yardstick competition, as with other forms of competition, is that it creates incentives for collusion. When regulated ..rms realise that they are played out against each other, they can be expected to take precautionary measures - to collude. The regulator may be forced to compensate ..rms for not colluding, which reduces the social value of yardstick competition. This paper studies optimal yardstick competition under the threat of collusion. As such, it adds to the mechanism design literature that emphasises collusion among agents as a source of inet ciency. ${ }^{2}$ The paper that lies the closest to this essay is Laxont and Martimort (1998b), henceforth abbreviated LM. LM consider, just as I do, collusion among agents with private, correlated information. The key dixerence is that $L M$ assume agents to have private information when they write collusive side contracts, whereas ..rms, in my setting, must form their cartel before the arrival of private information. Further, I assume that producers are unable to renegotiate the side contracts. Thus LM analyse collusion under asymmetric information, I study collusion under symmetric information.

The assumptions maintained here, are justi..ed on the following grounds. The purpose of yardstick schemes such as those in UK water supply and Norwegian electricity distribution, is to increase el ciency (reduce slack) in production. This

\footnotetext{
${ }^{2}$ Recent contributions include a sequence of papers by Laxont and M artimort (1997,1998a, 1998b). See also the references cited therein.
} 
means that collusion involves collective decisions about the level of el ciency to uphold in each ..rm. As slack cannot be changed ex post (after the period is over), ..rms must meet ex ante (in the beginning of the period) to decide on collusion. The running of a ..rm is a continuous process, which means that .rms do not know for sure what their future costs are going to be when they form the cartel. Changes in factor prices, break-down of machinery and other factors that axect production cost, occur regularly. Theoretically, ..rms could meet every time costs change and renegotiate their collusive contracts. However, this is cumbersome and increases the probability of detection. It therefore seems realistic to assume that collusion takes place in the anticipation that private information will arrive in the future and that this eventuality must be incorporated in the collusive side contract today.

I utilize a framework in which ..rm productivity is private information and consists of a ..rm-speci..c and an industry-speci..c part (Auriol and Laxont, 1992). The regulator applies yardstick competition to ...Iter out the common, industryspeci..c productivity parameter. Firms with high industry-speci..c productivity collude so as to restore informational rents. The anti-competitive exect of collusion creates a trade-ox between el ciency and rent-extraction. In the third-best, collusion-proof contract (i) ed ciency of low-productivity producers is distorted below the second-best (yardstick competition) level; (ii) high-productivity ..rms produce more el ciently than under second-best regulation. The ..rst exect re‡ects the possibility to increase rent-extraction from high-productivity ..rms by reducing the elc ciency of low-productivity ..rms. The second appears because nobody mimics a high-productivity ..rm under collusion, hence there is not much scope for distortions.

Collusion under asymmetric information involves the sharing of private information within the cartel. LM show how the regulator is sometimes able to exploit 
internal incentive problems. In particular, the regulator can set transfers so as to make collusion very expensive for the cartel when correlation of information is high. When correlation becomes near perfect, the regulator extracts almost all surplus from ..rms at in..nitesimal cost. The social cost of collusion vanishes in the limit. Here, ..rms do not exchange information, hence there are no incentive problems to be exploited. Contrary to the ..ndings of LM, the welfare loss of collusion persists in the almost perfectly correlated environment. In fact, the regulator is unable to extract any surplus at all. Collusion allows ..rms to behave as a merged entity; which enables them to fully oxset the exect of yardstick competition. The result suggests that cartel-formation with information-sharing may not the best collusive arrangement for regulated ..rms. Firms that cannot credibly transmit information to each other are better ox not exchanging information at all, but rather applying rules of the kind discussed in this paper.

The remainder of this paper is organised as follows: Section 2 formulates the model. In section 3 I present two benchmark cases: in the ..rst ..rms are regulated as separate entities, in the second yardstick competition is applied under the assumption that ..rms are unable to collude. Section 4 studies the incentives for collusion. Collusion-proof regulation is characterized in section 5. Lastly, section 6 concludes. Tedious proofs are collected in the appendix.

\section{The model}

\subsection{Technology and preferences}

In order to illustrate the assumptions of the model, I shall assume that the regulated industry is the water industry. The water industry consists of a number of regional natural monopolies that utilize a standardized technology for purifying drinking water and treating sewerage. The fact that ..rms use similar technolo- 
gies, plus a minimal scope for direct competition between the ..rms for customers, makes the industry a suitable candidate for yardstick competition (A rmstrong Cowan and Vickers, 1994). There are two regions ( $i=1 ; 2)$, each with an inelastic demand for $\mathrm{S}=2$ litres of water. ${ }^{3}$ Each region is served by a local water purifying plant that supplies the demanded water at cost:

$$
C_{i}={ }^{-}{ }_{i} e_{i}
$$

Cost depends on an exogenous parameter ${ }^{-}{ }_{i}$ and exort $e_{1}, \underline{e}$ exerted by management. Management's disutility of exort is

$$
\tilde{A}\left(e_{1}\right) \text { with } \tilde{A}(\underline{e}), 0, \tilde{A}^{0}>0, \tilde{A}^{\oplus}>0, \tilde{A}^{\infty}, 0 .
$$

Disutility of exort is always non-negative, it is increasing in exort at an increasing rate. Non-negativity of the third derivative is suф cient for concavity of the social planner's problem. The regulator only observes each producer's aggregate cost $\mathrm{C}_{i}$ and cannot disaggregate ${ }^{-}{ }_{i}$ and $e_{i}$ without an appropriate incentive contract. Water is puri..ed and sewerage is treated using a standardized technology. Hence, production cost depends in part on factors common to both ..rms. For example, a change in prices for chemicals for treating sewerage or a change in the cost of billing customers, should have the same impact on both producers' cost. P roduction cost is inłuenced also by factors speci..c to each region or ..rm, such as local pollution. When pollution increases, it becomes more costly to purify water. Local pollution is uncorrelated, therefore cost depends also on ..rm speci..c factors. I capture these exects by adopting the stochastic structure introduced by Auriol and Laxont (1992). The cost or productivity parameter ${ }^{-}$i consists of an industry speci..c part $\mathrm{m}$ (factor prices) and a ..rm speci..c part " ${ }_{i}$ (local pollution). Industry speci...c

\footnotetext{
${ }^{3} \mathrm{~T}$ he assumptions of inelastic demand and monopoly production are inconsequential to our analysis if ..rms produce at constant marginal cost. In that case the appropriate incentive contracts are independent of the pricing rule, see ch. 3 in Laxont and T irole (1993) - in particular their proposition 3.4.
} 
(IS) productivity $m$ is high $(m=\underline{m})$ with probability $v$ and low $(m=m)$ with probability $1 \mathrm{i}$ v. Firm speci... (FS) productivity ${ } i$ is continuously distributed on the interval ["; $\left.{ }^{*}\right]$ with strictly positive density $g(\Phi$ and cumulative distribution $G(\varnothing$. The hazard rate $G=g$ is assumed to be increasing, and I assume further that $m,{ }_{1}$ and " 2 are all stochastically independent. Total productivity is given by the weighted average:

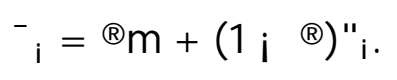

The weight $\circledast 2[@, 1]$ is common knowledge. Correlation of productivity is increasing in ${ }^{\circledR}$ and perfect at $\circledast=1$. I make the simplifying assumption that

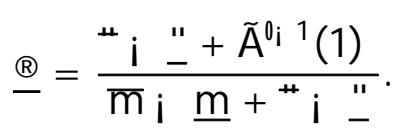

(2.3) and (2.4) imply that ${ }^{-}{ }_{i}$ is distributed over two disjoint intervals $A_{1}=\left[{ }^{-} ; a^{i}\right.$ ]

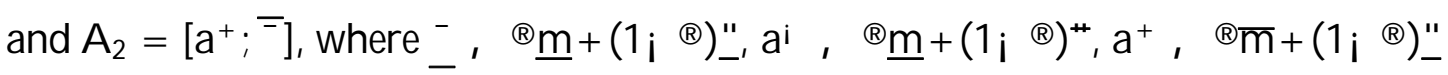
and $=$, $\quad \mathbb{m}+(1 ; \quad \mathbb{B})^{+4}$

Figure 1

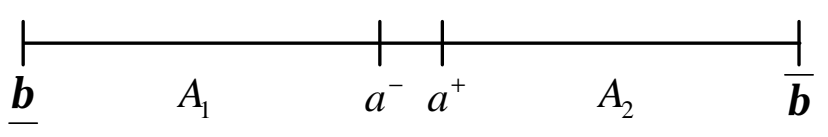

Both ..rms have productivity in $A_{1}$ if IS productivity is high $(m=\underline{m})$ and $A_{2}$ if IS productivity is low $(m=m)$. The regulator can use this information to ..Iter out the realization of the common parameter $m$. If ..rm 2 (1) were to operate at a cost that would imply a cost parameter somewhere in $A_{1}\left(A_{2}\right)$, the regulator would know that one of them were manipulating its cost. It can punish ..rms for making such incompatible cost reports, which then leads both ..rms to report cost in the correct interval (unless they are colluding). The analysis with overlapping

\footnotetext{
${ }^{4} T$ he second purpose of assumption (2.4) is to ensure that production cost $C_{i}$ be increasing in ${ }^{-}{ }_{i}$. It is further assumed that $m_{i} \underline{m}>\tilde{A}^{q}{ }^{1}(1)$ to keep the set of ${ }^{\circledR} s$ non-degenerate. For example, the condition is satis..ed for all $m>\underline{m}$ if $\tilde{A}(e)$, $\exp (e)$.
} 
intervals $A_{1}$ and $A_{2}$ is complicated and therefore skipped. ${ }^{5}$ Denote by $A=A_{1}\left[A_{2}\right.$ the support of ${ }^{-}{ }_{i}$. Subscripts $i$ and $j$ used to identify ..rms, is dropped in some of the analysis that follows. The reason is that ..rms are identical ex ante, hence are given identical regulatory contracts in equilibrium. Sometimes, I shall let ${ }^{-}$denote the type of a ..rm and ${ }^{-0}$ the type of the "other" ..rm. Write $F\left(^{-}\right)$the cumulative marginal distribution of ${ }^{-}$and $\left.\mathrm{f}^{-}{ }^{-}\right)$the corresponding density function. The hazard rate $F=f$ is a function of $G$ and $g$ and restrictions are put on $G$ suc cient to guarantee that even $F=f$ be increasing. ${ }^{6}$ The distribution of ${ }^{-0}$ conditional on ${ }^{-}, F\left(-g^{-}\right)$, is equal to $G\left({ }^{-} 9\right.$, where $G\left({ }^{-} 9, G\left(\frac{-0_{i} \circledast m}{I_{i} \circledast}\right)\right.$ with $m=\underline{m}$ for ${ }^{-} 2 A_{1}$ and $m=m$ for ${ }^{-} 2 A_{2}$. Density $f\left({ }^{-} g^{-}\right)=g\left(^{-} g\right.$ is de. ned correspondingly.

The..rm is fully compensated for its production cost $C_{i}$ and receives in addition a net transfer $t_{i}$ for serving its market. Hence ..rm i's rent is given by

$$
U_{i}=t_{i} i \tilde{A}\left(e_{i}\right) .
$$

Welfare equals

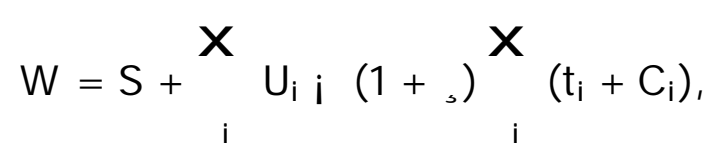

consumer surplus $\mathrm{S}$ plus the sum of ..rm rent $U_{i}$ minus the social cost of the gross transfer $\left(t_{i}+C_{i}\right)$ to each ..rm. , is the positive shadow price on public funds. As is now standard (2.1), (2.5) and (2.6) are manipulated to yield

$$
W=S_{i}(1+,)_{i}^{X}\left({ }_{i}^{-} i e_{i}+\tilde{A}\left(e_{i}\right)\right) i, U_{i} \text {. }
$$

\subsection{The regulatory contract}

The regulator proposes a direct revelation mechanism $D=\mathrm{ft} ; \mathrm{Cg}$ that speci..es a vector $t=\left(t_{1}(b) ; t_{2}(b)\right)$ of transfers to ..rms and a vector of cost targets

\footnotetext{
${ }^{5}$ T his is due to complicated second-order conditions of incentive compatibility constraints. But see A uriol (1993) for an analysis without collusion.

${ }^{6}$ See Auriol and Laxont (1992) for the details.
} 
$C=\left(C_{1}(b) ; C_{2}(b)\right)$ as a function of reported productivity $b=\left(b_{1} ; b_{2}\right) .{ }^{7}$

\subsection{The side contract}

A side contract $\$=f^{\circ} ;{ }^{\prime} g$ between ..rms consists of a set of mappings ${ }^{\circ}=$ $\left({ }_{1}^{\circ}\left({ }^{-}{ }_{1}\right) ;{ }_{2}{ }_{2}\left({ }^{-}\right)\right)$that speci..es which productivity ${ }_{i}^{\circ} .$. rm i should to report as a function of its realized productivity ${ }^{-}{ }_{i}$, plus a vector of inter-...rm transfers ${ }^{\prime}=$ (' $\left.{ }_{1}(\mathrm{~b}) ;{ }^{\prime}{ }_{2}(\mathrm{~b})\right)$ that depends on the vector of reported productivity b. Colluding ..rms agree on a rule that prescribes how each of them should report productivity, plus a set of side payments. The role of these side payments is to discipline ..rms to stick with the rule agreed upon. For simplicity, I impose a balanced budget constraint ' ${ }_{1}(b)=i{ }_{2}(b)$. De.ne

$$
Z_{i}\left(b_{i}{ }^{-}{ }_{i}\right), \quad{ }_{A}^{Z}\left[U\left(b_{i} i_{i} i^{\circ}{ }_{j}\left({ }^{-}{ }_{j}\right)\right)+{ }^{\prime}{ }_{i}\left(b_{i}{ }^{\circ}{ }_{j}\left({ }^{-} j\right)\right)\right] d F\left({ }^{-} j^{-}{ }_{i}\right),
$$

..rm i's expected utility of reporting $b_{1}$ contingent on productivity ${ }^{-}{ }_{i}$ and ...rm j reporting ${ }^{\circ}(\phi$. T wo natural restrictions are imposed on the set of admissible side contracts: feasibility and optimality.

De..nition 2.1. A side contract is said to be feasible if it satis..es:

$$
Z_{i}\left({ }^{-}{ }_{i}\right)=Z_{i}\left({ }^{\circ}{ }_{i}\left({ }^{-}{ }_{i}\right) i^{-}\right), Z_{i}\left(b_{i}{ }^{-}{ }_{i}\right) 8\left(b_{i} i^{-}{ }_{i}\right) 2 A^{2}, i=1 ; 2
$$

Feasibility is equivalent to incentive compatibility. Sticking with the side contract must be ..rm i's optimal strategy if it thinks that ..rm j will report according to ${ }_{j}(\phi$. Feasibility thus requires that ..rms cannot write contracts they are going to abandon later. Let - be the set of feasible side contracts, $\$$ and $\$$ two speci..c contracts in - , and denote by $\succsim_{i}$ ( $\Phi$ i's expected surplus when both ..rms abide by

\footnotetext{
${ }^{7} \mathrm{~T}$ his is equivalent to a regulatory contract that speci..es transfers as a function of realized cost if cost target $C_{i}$ is strictly increasing in ${ }^{-}{ }_{i}$ (Laxont and Tirole, 1993). It is easy to check that all the derived contracts in this paper have this property.
} 
the side contract $\$$. The second requirement is that the selected side contract be optimal.

De.nition 2.2. A feasible side contract $\$$ is said to be optimal if it satis..es:

$$
x_{i}^{Z} \varpi_{i}\left({ }^{-}\right) d F\left({ }^{-}{ }_{i}\right),{ }_{i}{ }_{A}^{Z} Z_{i}\left({ }^{-}\right) d F\left({ }^{-}{ }_{i}\right) 8 \$ 2-.
$$

The optimality requirement is quite obvious. It states that ..rms are going to write a particular side contract only if it is incentive compatible and maximises expected industry pro..ts.

\subsection{Timing}

I study a static game in which there is production only once. First, the regulator proposes the regulatory contract $D$. Second, each ..rm accepts or rejects; rejection leaves a ..rm with reservation utility 0 . If both ..rms agree to produce, they may write a side contract $\$$. Third, productivity is revealed and is the private information of each ..rm. Even at this stage ..rms have the opportunity to turn down both the regulatory and the side contract. Fourth, productivity is reported, transfers are paid out as speci..ed by the regulatory contract, and ..rms meet their corresponding cost target. Finally, side transfers, if any, are made.

The interim participation constraint of each ..rm is made for the sake of re alism. Normally ..rms have limited liability; owners are not liable for more than they have put into the ..rm. Consequently, an owner cannot be prevented from shutting down her ..rm if she ..nds production unpro.table. I assume that consumer surplus $\mathrm{S}$ is suф ciently high to guarantee that the regulator always ..nds it socially optimal to oxer a contract that satis..es this constraint. Enforceability of side transfers is normally justi..ed by a dynamic argument; ..rms who fail to comply are punished in subsequent periods. In the static setting there are no 
subsequent periods, hence side payments may not be possible. I study collusion under two alternative assumptions about the ability to commit to side payments: (i) .rms do not have access to side payments at all; (ii) ..rms can commit to unlimited side payments. Firms' unlimited access to side payments can be considered a worst-case scenario, and it de..nes an upper bound on what ..rms can achieve by colluding.

\section{R egulation in the absence of collusion}

In this section I derive a few regulatory contracts that will serve as benchmarks against which to evaluate the exects of collusion. The regulator maximizes expected welfare (subscript $\mathrm{i}$ is skipped throughout this section since both ..rms are identical ex ante and are given identical regulatory contracts):

$$
\left.\max _{f U(\phi ; e(\phi g} S=2 i_{A^{2}}^{Z}\left[(1+,)\left(^{-} i \quad e^{-}\right)+\tilde{A}\left(e\left(^{-}\right)\right)\right)+, U\left(^{-}\right)\right] d D^{-}\left(^{-}\right)
$$

subject to the incentive compatibility (IC) constraint:

$$
\mathrm{V}\left(\left(^{-}\right),{ }_{\mathrm{A}}^{\mathrm{Z}} \mathrm{U}\left({ }^{-}\right) \mathrm{dF}\left(\left(^{-} \mathrm{g}^{-}\right), \mathrm{V}\left(\mathrm{b} ;^{-}\right),{ }_{\mathrm{A}}^{\mathrm{Z}} \mathrm{U}\left(\mathrm{b} ;^{-}\right) \mathrm{dF}\left({ }^{-} \mathrm{g}^{-}\right) 8\left(\mathrm{~b} ; ;^{-}\right) 2 \mathrm{~A}^{2}\right.\right.
$$

and the interim participation (IR) constraint:

\section{Z}

$$
U\left(( ^ { - } ) \mathrm { dF } \left(\left(^{-} g^{-}\right), 08^{-} 2 \mathrm{~A} .\right.\right.
$$

$\left.\mathrm{p} \mathrm{(}^{-}\right)$is the joint cumulative distribution of ${ }^{-}$, where ${ }^{-}=\left(^{-} ;-9\right.$ is the vector of cost parameters. The IC constraint (3.2) requires that truth-telling maximize expected rents conditional on the ..rm's belief that the other ..rm report its true type too. The IR constraint (3.3) requires that all ..rms be willing to produce in equilibrium. Let ${ }_{-}^{-}\left(^{-}\right)$respective ${ }^{-}\left(^{-}\right)$denote the lower respective upper boundary of $A_{k}$ for ${ }^{-} 2 A_{k}$, and write $A_{k}^{c}$ the complement of $A_{k}, k=1 ; 2$. I sometimes refer 
to a regulatory contract that meets the IC constraint as a truthful mechanism. It is straightforward to verify that a contract is a truthful mechanism if and only if:

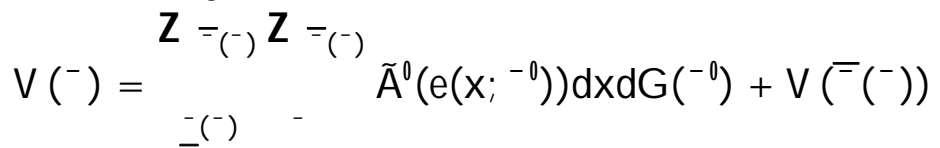

$$
\begin{aligned}
& V\left({ }^{-}\right), V\left(b ;{ }^{-}\right), 8\left(b ;^{-}\right) 2 A_{k} f A_{k}^{c}
\end{aligned}
$$

$$
\left.\mathrm{C}^{-}\right) \text {non-decreasing in }{ }^{-} 8^{-} 2\left[_{-}^{-}\left({ }^{-}\right) ;^{-}\left({ }^{-}\right)\right]^{2} \text {. }
$$

Note that expected rents are locally decreasing in ${ }^{-}$so $\mathrm{V}\left(\mathrm{a}^{\mathrm{i}}\right), 0$ and $\mathrm{V}\left(^{(}\right), 0$ are necessary and suф cient for (3.3) to be satis..ed.

\subsection{Individual regulation of ...rms}

This section considers individual regulation of ..rms. Collusion is of no concern under this regime because each ..rm's rent is independent of the other ..rm's performance. The maximization of (3.1) subject to (3.4)-(3.6) and (3.3), becomes:

$$
\max _{U(\phi ; e(\phi)} \frac{S}{2} i_{A}^{Z}\left[(1+,)\left(^{-} i e\left(^{-}\right)+\tilde{A}\left(e\left(^{-}\right)\right)\right)+, U\left(\left(^{-}\right)\right] d F\left(^{-}\right)\right.
$$

subject to the incentive compatibility (IC) constraints:

$$
\begin{gathered}
U\left(^{-}\right)={\stackrel{-}{\left.Z{ }^{-}\right)}}^{A^{q}}(e(x)) d x+U\left(^{(-}\left({ }^{-}\right)\right) \text {and } U\left(a^{i}\right), U\left(a^{+} ; a^{i}\right) \\
C\left(^{-}\right) \text {non-decreasing in }{ }^{-} 8^{-} 2\left[_{-}^{-}{ }^{-}\right] .
\end{gathered}
$$

and the interim participation (IR) constraint:

$$
U\left(^{-}\right), 0 .
$$

The last restriction in (3.8) does not appear in the standard analysis. It enters explicitly here due to non-convexity of A. Straightforward maximization of (3.7) subject to (3.8)-(3.10) yields optimal exort $\mathrm{e}^{\mathrm{s}}\left(^{-}\right)$implicitly de. ned by:

$$
\tilde{A} q\left(e^{s}\left({ }^{-}\right)\right)=1 i \frac{F}{1+,} \frac{F\left(^{-}\right)}{f\left(\left(^{-}\right)\right.} \tilde{A}\left(e^{s}\left(^{-}\right)\right) 8^{-} 2\left[_{-}^{-} ; a^{i}\right]\left[\left[^{-s} ;^{-}\right]\right. \text {. }
$$


This is the standard solution. Note however, that, due to non-convexity of $A$, there is some bunching at the optimum, i.e. all ..rms of type ${ }^{-} 2\left[\mathrm{a}^{+} ;^{-\mathrm{s}}\right)$ meet the same cost target $\mathrm{C}^{s}\left({ }^{-s}\right)$. Thus ${ }^{8}$

$$
\mathrm{e}^{\mathrm{s}}\left({ }^{-}\right)=\mathrm{e}^{\mathrm{s}}\left({ }^{-s}\right)+{ }^{-} \mathrm{i}^{-\mathrm{s}} 8^{-} 2\left[\mathrm{a}^{+} ;^{-\mathrm{s}}\right) .
$$

\subsection{Yardstick competition}

Yardstick competition allows the regulator to costlessly ...ter out the industryspeci..c (IS) parameter $m$. $m$ is perfectly correlated across ..rms so productivity - is either in $A_{1}(m=\underline{m})$ for both producers or $A_{2}(m=m)$ for both producers. The two ..rms know this and so does the regulator. The only way a ..rm is going to enjoy rents for high IS productivity is by mimicking a low IS producer, i.e. by reporting b $2 A_{2}$. In this standard, non-collusive setting each ..rm trusts the other to truthfully reveal its type ${ }^{-0} 2 A_{1}$. Therefore, a deviation is expected to lead to incompatible productivity reports, $b 2 A_{2}$ and ${ }^{-0} 2 A_{1}$. The regulator can costlessly remove this incentive by refusing to pay any transfers in case of incompatible reports. Dalen (1998) shows that optimal exort $\mathrm{e}^{\mathrm{yc}}\left(^{-}\right)$under yardstick competition is the solution to: ${ }^{9}$

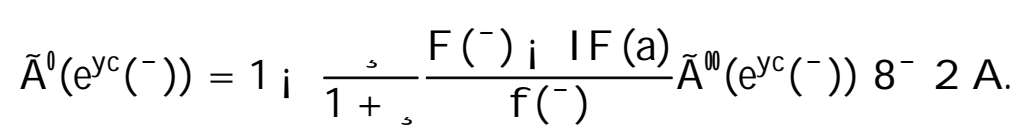

$I$ is an indicator function that takes on the value 1 for ${ }^{-} 2 A_{1}$ and zero otherwise. A comparison of exort levels under individual regulation and yardstick competition shows:

Proposition 3.1. (Dalen, 1998) Optimal contracts arecharacterized by $(\mathrm{i}) \mathrm{e}^{\mathrm{s}}\left(^{-}\right)=$ $\mathrm{e}^{\mathrm{yc}}\left(^{-}\right)$for all ${ }^{-} 2 \mathrm{~A}_{1}$ and; (ii) $\mathrm{e}^{\mathrm{s}}\left(^{-}\right)<\mathrm{e}^{\mathrm{yc}}\left(^{-}\right)$for all ${ }^{-} 2 \mathrm{~A}_{2}$.

\footnotetext{
${ }^{8}$ Se appendix A.1 for a derivation of the optimal contract and optimal level of bunching ${ }^{-s}$. ${ }^{9}$ See also AL for the derivation of a similar expression.
} 
Exort is distorted below ..rst best in order to extract rents from high productivity ..rms. Rents must be given up to ..rms with high industry-speci..c productivity under individual regulation so as to prevent them from understating productivity and reporting ${ }^{-} 2 A_{2}$. This is not necessary under yardstick compe tition. Hence, the marginal rent extraction is larger under individual regulation than under yardstick competition. This calls for larger distortions of exort in the former than latter case.

\section{Collusion}

The socially optimal exort level $e^{y c}(\Phi$ is attained under the assumption that each ..rm believes the other to truthfully report productivity. This allows the regulator to costlessly extract information about industry-speci..c (IS) productivity by punishing ..rms for delivering incompatible productivity reports. It is evident that ..rms may have an incentive to coordinate on compatible reports so as to get around yardstick competition. Suppose that ..rms have agreed to pretend they have low IS productivity and maximum ..rm-speci..c productivity whenever they in reality have high IS productivity, i.e. report $a^{+}={ }^{\circledR} m+\left(1_{i}{ }^{\circledR}\right)_{-}^{\prime \prime}$ for all ${ }^{-} 2 A_{1}$. The rent is $U^{\mathrm{yc}}\left(\mathrm{a}^{+} ;{ }^{-}\right)=\mathrm{t}^{\mathrm{yc}}\left(\mathrm{a}^{+}\right)$i $\tilde{A}\left({ }^{-}\right.$; $\left.C^{\mathrm{yc}}\left(a^{+}\right)\right)$for the ..rm of type ${ }^{-} 2 \mathrm{~A}_{1}$ under the collusive agreement. The expected rent when both ..rms truthfully reveal productivity is $\mathrm{U}^{\mathrm{yc}}\left(^{-}\right)=\mathrm{t}^{\mathrm{yc}}\left(^{-}\right)$; $\tilde{A}\left(\mathrm{e}^{\mathrm{yc}}\left(^{-}\right)\right)$. The dixerence is:

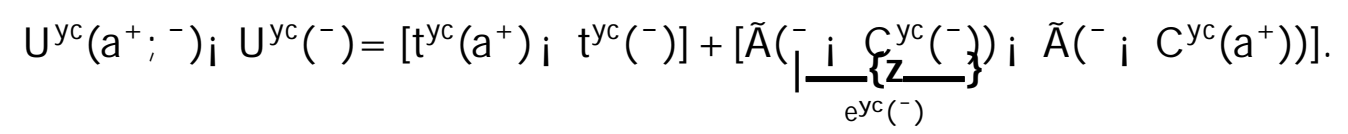

When both ..rms understate productivity, transfers and cost targets change. The

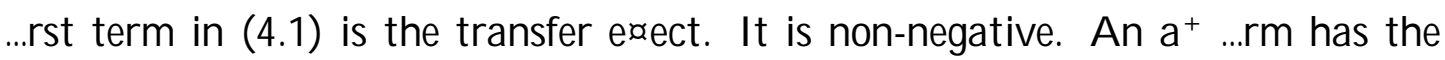
highest possible FS productivity and thus exerts the highest exort in equilibrium (equation (3.13)). Therefore it must receive the maximum transfer in order to be 
willing to produce at all. ${ }^{10}$ Furthermore, producers are able to credibly in $¥$ ate costs from $\mathrm{C}^{\mathrm{yc}}\left({ }^{-}\right)$to $\mathrm{C}^{\mathrm{yc}}\left(\mathrm{a}^{+}\right)$(shirk) under collusion. ${ }^{11}$ The second term, the cost exect, is thus strictly positive. To summarize; $\underline{m}$..rms that coordinate reports on $\mathrm{a}^{+}$instead of telling the truth, receive more money for less work. This indicates that the regulator is going to have a problem with ..rms with high IS productivity collectively acting as if they have low IS productivity. Moreover, it is not diф cult to show that $m$..rms never have an incentive to overstate productivity (report b2 $A_{1}$ ). They would then have to satisfy more ambitious cost targets, the disutility of which would never be compensated by the extra transfers they might receive.

\section{Collusion-proof regulation}

In the previous section I argued that ..rms have an incentive to collude by collectively understating productivity. This section analyses the regulator's optimal response to collusion. Attention is restricted to the class of collusion-proof mechanisms. De.ne the truthful side contract to be the side contract in which no side payments are made and ..rms agree on truthful revelation of productivity. A regulatory contract is said to be collusion-proof if it is induces ..rms to select the truthful side contract. Under collusion-proof regulation, the regulator faces the following maximization problem (again subscript $i$ is dropped on the regulatory contracts to save on notation):

$$
\begin{gathered}
\left.\max _{f \cup(\phi ; e(\phi g)} S=2 i_{A^{2}}^{Z}\left[(1+\ldots)\left(^{-} i \quad e^{-}\right)+\tilde{A}\left(e\left(^{-}\right)\right)\right)+, U\left(^{-}\right)\right] d P\left(D\left(^{-}\right)\right. \\
\text {s.t. } V\left(^{-}\right), V\left(b ;^{-}\right) 8\left(b ; ;^{-}\right) 2 A^{2},
\end{gathered}
$$

\footnotetext{
${ }^{10} \mathrm{tyc}^{\mathrm{c}}\left(^{-}\right)=\mathrm{U}^{\mathrm{yc}}\left(\left(^{-}\right)+\tilde{\mathrm{A}}\left(\mathrm{e}^{\mathrm{yc}}\left(^{-}\right)\right)\right.$. M oreover $\mathrm{U}^{\mathrm{yc}}\left(^{-}\right)=\stackrel{\mathrm{R}^{-}}{-\left(^{-}\right)} \tilde{\mathrm{A}}^{\mathrm{Q}}\left(\mathrm{e}^{\mathrm{yc}}(\mathrm{x})\right) \mathrm{dx}$. Therefore $\mathrm{t}^{\mathrm{yc}}\left(^{-}\right)=$ $\mathrm{i}\left(1 \mathrm{i} \mathrm{e}^{\mathrm{yc}}\left(^{-}\right)\right) \tilde{A}^{0}\left(\mathrm{e}^{\mathrm{yc}}\left(^{-}\right)\right)<0$. Symmetry of contracts imply $\mathrm{t}^{\mathrm{yc}}\left({ }_{-}^{-}\right)=\mathrm{t}^{\mathrm{yc}}\left(\mathrm{a}^{+}\right)$, which establishes $\mathrm{t}^{\mathrm{yc}}\left(\mathrm{a}^{+}\right)$as the global maximum.

${ }^{11}$ See appendix A.2 for a formal proof that cost is strictly increasing in - under regular yardstick competition.
} 


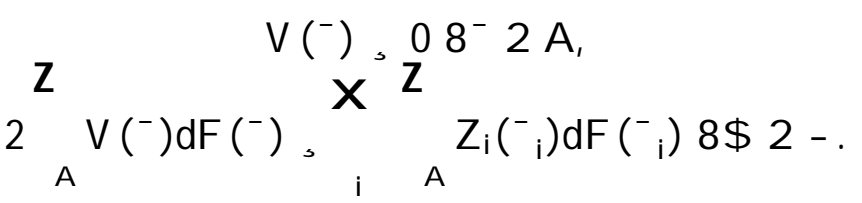

Expected welfare is maximised under the conditions that the truthful side contract be feasible (constraint (5.2)), that all ..rms be willing to produce under truthful revelation of productivity (constraint (5.3)) and that the truthful side contract maximise expected industry pro..ts under all feasible side contracts (constraint (5.4)).

Our interest in collusion-proof regulation stems from the fact that the welfare maximizing regulatory contract can be rewritten as a collusion-proof contract. The intuition behind this Collusion-proofness Principle is the same as that underlying the Revelation Principle. Given her knowledge about the collusive agree ment, the regulator can tailor transfers and cost targets so as to construct an incentive compatible, truthful side contract that is identical to the optimal collusive side contract, hence generates the same expected industry pro..ts. Exort and rents are the same under the new collusion-proof contract as under the original contract, hence expected welfare is the same. Formally: ${ }^{12}$

Proposition 5.1. Assume that ..rms can write and enforce collusive side contracts of the form discussed in section 2.3. For every welfare maximising regulatory contract, there exists a collusion-proof regulatory contract that generates the same expected welfare.

Proof. Write $D^{x}=\mathrm{ft}^{\mathrm{x}} ; \mathrm{C}^{x} \mathrm{~g}$ the welfare maximising mechanism and $\$^{x}=$ $f^{\circ x ;}{ }^{x} g$ the corresponding optimal side contract. De. ne the regulatory con-

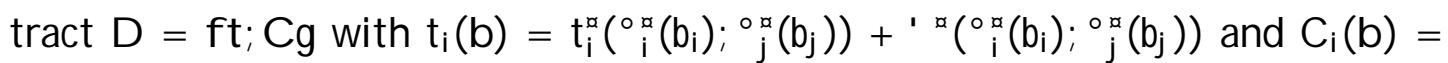

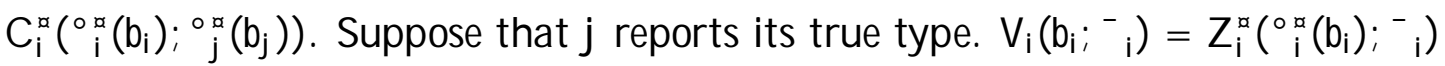

\footnotetext{
${ }^{12}$ Confer Laxont and Martimort (1997 and 1998b) for proofs of the Collusion-proofness Principle in dixerent contexts.
} 
implies $V_{i}\left({ }^{-}{ }_{i}\right)=\max V_{i}\left(b_{i}{ }^{-}{ }_{i}\right)$ by feasibility of $\$^{\circledR}$. This implies that the truthful side contract is feasible under $D . V_{i}\left({ }^{-}{ }_{i}\right)=Z_{i}^{a}\left({ }_{i}^{-}\right) 8^{-} 2 \mathrm{~A}$ implies collusionproofness of $D$ by the assumption that $\$^{x}$ is optimal. It further implies that individual rationality is met. Finally, $C_{i}\left({ }^{-}\right)=C_{i}^{a}\left({ }^{-}\right), U_{i}\left({ }^{-}\right)=U_{i}^{a}\left({ }^{-}\right)$and $\mathrm{t}_{1}\left(\left(^{-}\right)+\mathrm{t}_{2}\left(\left(^{-}\right)=\mathrm{t}_{1}^{\mathrm{a}}\left(\left(^{-}\right)+\mathrm{t}_{2}^{\mathrm{x}}\left(\left(^{-}\right)+{ }^{\prime \mathrm{x}}\left({ }^{-}\right) \mathrm{i}^{\prime}{ }^{\mathrm{x}}\left(^{-}\right)\right.\right.\right.\right.$imply that welfare is unchanged.

Two restrictions have been put on the admissible side contract: i) that it be feasible, i.e. it must be in each ..rm's best interest to adhere to the side contract if it believes that the other ..rm will do so; ii) that it be optimal, i.e. ..rms pick the side contract that maximises expected industry pro..ts. This means that the regulator can ward ox collusion either by rendering every collusive side contract infeasible, or by reassuring that the most pro..table side contract be the truthful one. As we shall see, the optimal strategy depends on ..rms' access to side payments. T wo cases are considered. First, I assume that ..rms cannot commit to side payments at all. This could be relevant, since the model considered here is a one-shot game. This is the best-case scenario, as access to side payments facilitates collusion. At the other extreme is the worst-case scenario where ..rms can commit to unlimited side payments. This case is studied in section 5.2.

\subsection{The best-case scenario: no access to side payments}

The discussion in section 4 showed that high productivity ..rms want to coordinate on a side contract that understates productivity. B ut is it suc cient that ..rms agree to coordinate on productivity reports? In other words, is it possible to uphold collusive agreements in the absence of side payments? The answer is no. Firms cannot collude unless they can commit to side payments. ${ }^{13}$ The reason is that the regulator can break any collusive agreement by the appropriate design

\footnotetext{
${ }^{13}$ However, the absence of observed transfers cannot be taken as evidence that collusion is impossible. In the model side transfers are used as a punishment mechanism to discipline ..rms. Non-existence of side transfers could imply that ..rms cannot collude, but it could equally well be explained by disciplined collusive behaviour.
} 
of sticks and carrots. Suppose that the regulator oxers a huge bonus to the high productivity producer in case of incompatible reports. M ost yardstick competition schemes have the property that a high-performance ..rm receives a higher payment than a low-performance..rm. It is easy to see that there exists a carrot suф ciently big to break every collusive agreement to report low productivity (see appendix A.2 for an example of such a contract). By oxering a suф ciently big carrot to the deviator, the regulator can costlessly prevent collusion. Bonuses are not paid out in equilibrium, hence welfare is not diminished by the restriction that regulation be collusion-proof:

Proposition 5.2. Assume that ..rms do not have access to side payments. Then there exists a regulatory contract that implements second-best exort $e^{y c}(\phi$ as a unique Bayesian Nash equilibrium (BNE). It has the additional property that truth-telling is a strictly dominating strategy for all ${ }^{-} 2\left[_{-}^{-} ; a^{i}\right)$.

Proof. See appendix A.2.

W ithout inter-..rm transfers, collusion must be of the form that ..rms coordinate on a particular BNE. However, the only BNE is in truth-telling strategies, hence collusion is impossible.

\subsection{The worst-case scenario: unlimited access to side payments}

If ..rms can pay transfers to each other, collusion is a serious concern, simply because any sticks and carrots oxered by the regulator can be neutralised by ..rms' choice of side payments:

Proposition 5.3. Assume that ..rms have access to unlimited side payments and that the regulator oxers the second-best contract. In that case, there exists a feasible collusive side contract that yields strictly higher expected industry pro..ts than the truthful side contract. 
Proof. Yardstick competition is a truthful mechanism. This implies, by lemma A.2 in the appendix, that there exists a feasible side contract $\$$ with the properties ${ }^{\circ}\left(^{-}\right)=a^{+} 8^{-} 2 A_{1}$ and ${ }^{\circ}\left(^{-}\right)={ }^{-}$otherwise. $Z\left(^{-}\right)=V\left(^{-}\right) 8^{-} 2 A_{2}$ and $Z\left(^{-}\right)=U^{y c}\left(a^{+} ;{ }^{-}\right) 8^{-} 2 A_{1}$ imply that $\$$ strictly outperforms truth-telling because $\left.\mathrm{U}^{\mathrm{yc}}\left(\mathrm{a}^{+} ;^{-}\right)>\mathrm{U}^{\mathrm{yc}}\left(^{-}\right)=\mathrm{V}^{-}\right) 8^{-} 2 \mathrm{~A}_{1}$, as shown in section 4 .

Proposition 5.3 states that there exists no collusion-proof regulatory contract that implements second-best exort. Thus, the regulator is forced give up rents to ..rms in order to implement collusion-proof regulation. This creates a trade-ox between ed ciency and rent-extraction. I show in appendix A.3 that the binding collusive incentive constraint is:

$$
Z_{-}^{a_{i}} V\left(( ^ { - } ) d F \left(\left(^{-}\right)=Z_{-}^{Z_{a i}}\left(t^{+} ; \tilde{A}\left(\left(^{-} ; C^{+}\right)\right) d F\left(\left(^{-}\right),\right.\right.\right.\right.
$$

where $\mathrm{t}^{+}$is the transfer to each ..rm if they both report $\mathrm{a}^{+}$, and $\mathrm{C}^{+}$is the corresponding cost-target. Collusion-proof regulation requires that expected industry pro..ts under truth-telling equal expected industry pro..ts of a side contract in which ..rms report their true type whenever the have low industry-speci..c (IS) productivity $\left({ }^{-} 2\left[a^{+} ;^{-}\right]\right)$and $a^{+}$otherwise. This is what I hinted at in section 4: the fundamental problem with collusion is that ..rms with high IS productivity have an incentive to collusively pretend they have low IS productivity and simultaneously high ..rm-speci..c (FS) productivity (report $b=a^{+}$). This strategy maximises transfers while allowing a generous cost target.

Equation (5.5) shows that the social cost of collusion, i.e. ..rm rents, is de. ned entirely by transfers to and cost targets for producers with low IS productivity. This has two implications. First, it increases the marginal value of ed ciency distortions for low productivity ..rms. Suppose that an $\mathrm{a}^{+} . . \mathrm{rm}$ is allowed a slightly more generous cost target than under second-best regulation. This implies that the transfer to the $a^{+} . . r m$ can also be reduced to keep the ..rm indixerent between 
the new and the old contract. Due to convexity of the disutility function $\tilde{A}$, it is more valuable to a low productivity ..rm than to a high productivity ..rm to be allowed to in ate costs. A reduction in transfers that keeps a low productivity ..rm equally well ox as before, has the implication that collusion becomes less valuable because the reduction in transfers more than oxsets the value of the infated cost target for the ..rm with high IS productivity. The implication is that marginal distortion of exort below its second-best level for low-type ..rms increases rentextraction from high-type ..rms. Second, collusion reduces the marginal value of etc ciency distortions for high IS productivity ..rms. The problem with collusion is not that low productivity ..rms pretend that they have high productivity; it is the opposite. There is little to gain in terms of rent extraction by distorting el ciency of high-productivity ..rms. This means that collusion-proof regulation demands stronger incentives for cost reduction than the second-best contract for ..rms with high IS productivity. The analysis below provides the formal solution to the regulator's problem.

A ppendix A.3 shows that the maximization problem (5.1)-(5.4) can be rewritten as:

$$
\begin{aligned}
& \left.\max _{e(\phi)} \frac{s}{2} i(1+,)_{A}^{R}\left({ }^{-} i e^{-}\right)+\tilde{A}\left(e\left(^{-}\right)\right)\right) d F\left(\left(^{-}\right) i,\left[_{a^{+}}^{R-} \tilde{A} q\left(e^{-}\right)\right) \frac{F\left(\left(^{-}\right)\right.}{f\left(\left(^{-}\right)\right.} d F\left(^{-}\right)\right. \\
& \left.\left.+{ }_{-}^{-} \tilde{A} q^{-} ; a^{+}+e\left(a^{+}\right)\right) \frac{F\left(^{-}\right)}{f\left(\left(^{-}\right)\right.} d F\left(\left(^{-}\right)+\underset{a^{i}}{R_{a^{+}}} \tilde{A} q x ; a^{+}+e\left(a^{+}\right)\right) d x F(a)\right] \\
& \text { s.t. } \left.\mathrm{C}^{-}\right) \text {non-decreasing on }{ }^{-} 2\left[_{-}^{-}\left({ }^{-}\right) ;^{-}\left({ }^{-}\right)\right] \text {, } \\
& \text { and }{ }_{-}^{Z_{a i}}\left(t ^ { + } i \tilde { A } ( ( ^ { - } i C ^ { + } ) ) d F ( ( ^ { - } ) , \quad { } ^ { a ^ { i } } \tilde { A } q e ( ^ { - } ) ) \frac { F ( ( ^ { - } ) } { f ( ^ { - } ) } d F \left(\left(^{-}\right)\right.\right. \text {. }
\end{aligned}
$$

The second term in (5.6) is the social cost of production, and the long term in brackets is the expected rent. The constraint (5.8) is the participation constraint of the ..rm with productivity ai (see appendix A.3). Not too surprisingly it shows that the harder high-productivity ..rms must work, the less likely it is that the 
constraint be satis..ed. The standard procedure to derive the socially optimal amount of exort would be to solve (5.6) as an unconstrained problem and verify ex post that (5.7) and (5.8) were met. This is not possible here because (5.7) is binding. J ust like in the case with separate regulation of ..rms, there is some bunching at the optimum. Further, (5.8) may be binding too. Let ${ }^{-c p}$ denote the optimal level of bunching, that is let all ..rms with productivity in $\left[\mathrm{a}^{+} ;^{-}{ }^{\mathrm{cp}}\right.$ ) be given the cost target $C\left(^{-\mathrm{cp}}\right) .{ }^{14}$ Denote by $\mathrm{W}^{\mathrm{cp}}(\phi$ expected welfare (5.6) under collusion-proof regulation and form the Lagrangian:

$$
\left.\left.L=W^{c p}+{ }^{1} Z_{a^{i}}\left(t^{+} ; \tilde{A}\left(^{-} ; C^{+}\right) \text {i } \tilde{A} q e^{-}\right)\right) \frac{F\left(^{-}\right)}{f\left(^{-}\right)}\right) d F\left(^{-}\right)
$$

${ }^{1}$ is the Lagrange multiplicator. M aximizing over exort gives the following ..rstorder conditions:

$$
\begin{aligned}
& \left.\tilde{A} q\left(e^{c p}\left(^{-}\right)\right)=1 i \frac{1}{1+,} \frac{F\left(^{-}\right)}{f\left(\left(^{-}\right)\right.} \tilde{A} \mathscr{\Psi} e^{c \mathcal{P}}\left({ }^{-}\right)\right) 8^{-} 2\left[_{-}^{-} ; a^{i}\right], \\
& \tilde{A} q\left(e^{c p}(-)\right)=1 i \frac{,}{1+,} \frac{F\left(^{-}\right)}{f\left(\left(^{-}\right)\right.} \tilde{A} q\left(e^{c p}\left(^{-}\right)\right) 8^{-} 2\left[^{-c i_{i}}{ }^{-}\right] \text {, }
\end{aligned}
$$

where $\mathrm{e}^{\mathrm{cp}}\left(^{-}\right)$denotes optimal level of exort under collusion-proof regulation. As al ready mentioned, all ..rms with productivity in $\left[a^{i} ;^{-{ }^{c p}}\right.$ ) produce at the same cost. Consequently, exort equals

$$
e^{c p}\left(^{-}\right)=e^{c p}(-c p)+{ }^{-} i^{-c p} 8^{-} 2\left[a^{+} ;^{-c p}\right) .
$$

A comparison of optimal exort (5.10)-(5.12) under collusion-proof regulation with optimal exort (3.13) under regular yardstick competition con..rms our expectations:

Proposition 5.4. Third best, collusion-proof regulation entails more (less) distortion of exort for ..rms with low (high) industry-speci..c productivity than second-best regulation.

\footnotetext{
${ }^{14}$ The optimal level of buching under collusion-proof regulation is derived in appendix A.4.
} 
Proof. See appendix A.4.

An central proposition in Laxont and Martimort (1998) (LM) states that the social cost of collusion vanishes in the limit when correlation of information be comes near perfect. The reason is that the regulator is able to exploit informational asymmetries within the cartel to extract almost all rents. Here, ..rms never share information. Therefore there are no informational asymmetries for the regulator to exploit. As we shall see, the welfare implication is fundamentally dixerent.

To see what happens when correlation of information changes, subtract expected welfare $W^{s}$ when ..rms are regulated on an individual basis (equation (A .3) in appendix $A .1$ ) from expected welfare $W^{\mathrm{cp}}$ under collusion-proof regulation to obtain:

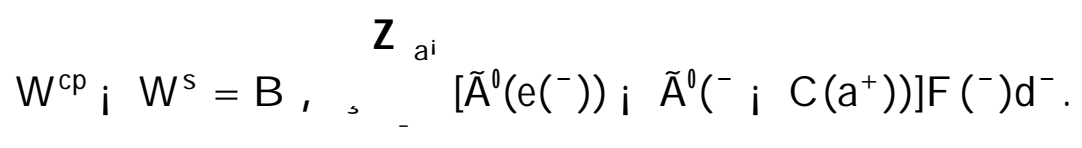

$B$ is the bene..t of yardstick competition. Under individual regulation a ..rm with high IS productivity $(\mathrm{m}=\underline{\mathrm{m}})$ can credibly mimic a ..rm with low IS productivity $(\mathrm{m}=\mathrm{m})$. This means that every ..rm with high IS productivity must be compensated for not understating productivity to $\mathrm{a}^{+}$under separate regulation. Under collusion-proof yardstick competition, an $\underline{\mathrm{m}}$..rm cannot credibly pretend to be an $\mathrm{m}$..rm. It would involve incompatible reports, for which they are punished. However, the regulator must pay ..rms ex ante for not agreeing to manipulate reports. A deviation must be unpro..table in expectation. In a sense one can say that yardstick competition allows the regulator to switch from an ex post to an ex ante incentive constraint for $\underline{m}$..rms. B measures the social value of the reduction in expected transfers attributed to the change from the ex post to the ex ante incentive constraint. 
Proposition 5.5. The bene..t (B) of yardstick competition vanishes when correlation of private information (measured by ${ }^{\circledR}$ ) becomes perfect.

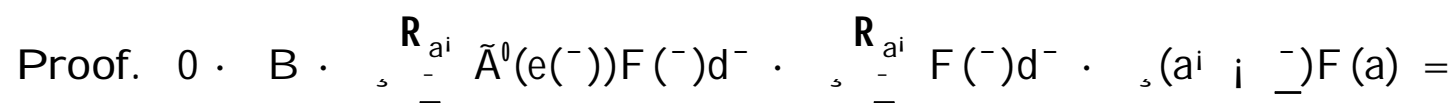
, $\left(1_{i}{ }^{\circledR}\right)\left({ }^{*} i_{-}\right) v$. The ..rst inequality follows from monotonicity of $C$, the second from $\tilde{A}^{0}>0$, the third from $\left.\left.\tilde{A} 9 e^{-}\right)\right) \cdot 1$ and the fourth from $F^{0}>0$. It is evident that $B$ ! 0 when ${ }^{\circledR}$ ! 1 .

Proposition 5.5 combined with expression (5.13) shows that collusion-proof regulation converges to individual regulation of ..rms when correlation becomes high. Contrary to the LM case, ..rms recover all their losses in a perfectly correlated environment, when collusion is possible. Collusion allows producers to act as a merged entity, thereby fully countervailing the rent-extraction exect of yardstick competition. The result suggests that cartel-formation with information-sharing may not the best collusive arrangement for regulated ..rms. Highly similar ..rms who cannot credibly transmit information to each other, are better ox not exchanging information, but rather applying rules of the kind discussed in this paper. ${ }^{15}$ The explanation for the result lies in the restrictions the dixerent modes of collusion puts on side transfers. In the LM model the two agents report their true type to a third party that uses the information to manipulate the social planner's mechanism. This puts a lot of restrictions on the side payments. A massive side transfer may be required in order to induce agent 1 to truthfully reveal his type, but the huge side transfer may have the implication that it becomes unpro..table for agent 2 to reveal his type or even participate in the cartel. What LM show, is that although the stakes of collusion increase when correlation of types becomes stronger, there is no way the agents can set up side transfer schemes to reap the bene.ts. Not so in this model. Here, the value of side transfers is measured solely by the pain it inficts on the potential deviator. The value does not matter to the

\footnotetext{
${ }^{15} \mathrm{~T}$ his presupposes that the regulator knows the mode of collusion.
} 
recipient since ..rms do not share information in the ..rst place. Thus .rms are able to neutralise any sticks and carrots oxered by the regulator, irrespective of the degree of collusion

Finally, a word on collateral. The ..rst-best regulatory contract is to give each ..rm a ..xed-price contract, which maximises eq ciency in production, and pay out transfers suф cient to guarantee that ..rms' ex ante participation constraint is just met. This is even collusion-proof since each ..rm is regulated on an individual basis. However, the contract implies that some low-productivity ..rms run a de..cit ex post, hence shut down. The interim participation constraint can be relaxed by the use of collateral. If ..rms put up suф cient collateral, they are willing to produce at all levels of productivity even with a ..xed-price contract. The problem is that ..rms realise that rents are decreasing in the amount of collateral they put up. Consequently, they have no incentive to provide it. A potential method for raising collateral is by means of an auction where the right to produce goes to the ..rm with the highest collateral. However, the set of potential bidders may be small and their access to collateral limited. Therefore, the regulator may be forced to use yardstick competition in regulation. Collateral must be in the form of lump sum payments, in order to preserve truth-telling incentives. It can have no exect on ..rms' joint exorts to manipulate incentive contracts because they retrieve their collateral whether they collude or not as long as they keep producing. The conclusion is that the use of collateral can be used as an instrument to increase eф ciency in production, but not to prevent collusion - unless ..rms are willing to put up signi..cant amounts of it. 


\section{Conclusion}

This paper has studied the nature of collusion and characterized collusion-proof regulation when ..rms are regulated by means of yardstick competition and have the opportunity to write collusive side contracts prior to the revelation of private, correlated information. High productivity ..rms collectively pretend to have low productivity in order to circumvent the exects of yardstick competition. They must be compensated for not colluding, which creates a trade-ox between rentextraction and et ciency. Collusion-proof yardstick competition demands less (more) cost et cient production for low (high) productivity ..rms than prescribed by regular (second-best) yardstick competition. It has been shown that colluding ..rms are able to recover almost all rents when correlation of information is near perfect. This contrasts with the result by Laxont and Martimort (1998b), that ..rms are able to recover almost no rents when information is highly correlated. The divergent welfare implications stem from assumptions about timing. Firms collude after the revelation of private information in the Laxont and Martimort framework, whereas they form the cartel prior to the revelation of private information in my setting. This suggests that regulated ..rms may want to commit to not exchanging information when they form cartels.

\section{R eferences}

[1] A rmstrong, Mark, Simon Cowan and J ohn Vickers (1994): Regulatory Reform: Economic Analysis and British Experience, Cambridge, MA: MIT Press.

[2] Auriol, Emmanuelle (1993): "M onopole ou duopole: L'exet de comparaison ," Annales d'Economique et de Statistique 31: 1-31.

[3] A uriol, Emmanuelle and J ean-J acques Laxont (1992): "Regulation by duopoly," J ournal of Economics and Management Strategy 1: 507-533.

[4] Baiman, Stanley and J oel S. Demski (1980): "E conomically optimal performance evaluation and control systems," J ournal of Accounting Research 18 (supp): $184-220$. 
[5] Cowan, Simon (1997): "Competition in the water industry," Oxford Review of Economic Policy 13: 83-92.

[6] Dalen, Dag M. (1998): "Yardstick competition and investment incentives," J ournal of E conomics and Management Strategy 7: 105-126.

[7] Dalen, Dag M., Espen Moen and Christian Riis (1998): "Innteksregulering - gir det mer exektiv kontroll av nettmonopolene enn avkastningsregulering? (Income regulation - does it provide a more eq cient control over network monopolies than rate-of-return regulation?)" Report prepared for the Norwegian Water Resources and Energy Directorate (NVE).

[8] Demski, J oel S. and David E.M. Sappington (1984): "Optimal incentive contracts with multiple agents," J ournal of E conomic Theory 53: 152-171.

[9] Holmström, Bengt (1982): "Moral hazard in teams," Bell J ournal of Economics 13: 324-340.

[10] Laxont, J ean-J acques and David M artimort (1997): "Collusion under asymmetric information," Econometrica 65: 875-911.

[11] Laxont, J ean-J acques and David M artimort (1998a): "Collusion and delegation," RAND J ournal of Economics 29: 280-305.

[12] Laxont, J ean-J acques and David Martimort (1998b): "Mechanism design with collusion and correlation," mimeo, IDEI, Toulouse.

[13] Laxont, J ean-J acques Laxont and J ean T irole (1993): A Theory of Incentives in Procurement and Regulation, Cambridge, MA: MIT Press.

[14] Lazear, Edward P. (1995): Personnel Economics, Cambridge, MA: MIT Press.

[15] Mizutani, Fumitoshi (1997): "E mpirical analysis of yardstick competition in the J apanese railway industry," International J ournal of Transport E conomics 24: 367-392

[16] Nalebux, Barry J . and J oseph E. Stiglitz (1983): "P rizes and incentives: towards a general theory of compensation and competition," B ell J ournal of Economics 14: 21-43.

[17] Rappaport, Alfred (1999): New thinking on how to link executive pay with performance," Harvard Business Review 77: 91-101.

[18] Review of Commonwealth/ State Service Provision (RCSSP) (1999): "R eport on Government Services 1999," A usinfo, Catalogue no. 9812595.

[19] Shleifer, A ndrei (1985): "A theory of yardstick competition," RAND J ournal of Economics 16: 319-327.

[20] Sobel, J oel (1999): "A reexamination of yardstick competition," J ournal of Economics and Management Strategy 8: 33-60. 
[21] Yaisawarng, Suthathip and Nara Puthucheary (1997): "Performance measurement and resource allocation," New South Wales Treasury R esearch and Information Paper TRP 97-9.

[22] Y Ivinger, Svante (1998): "The operation of Swedish motor-vehicle inspections: eq ciency and some problems concerning regulation," Transportation 25: $23-36$.

\section{A. A ppendix}

I ..rst prove some intermediary results. Write $b=(b ; b 9$, and let $t(b), U(b)$, $\mathrm{C}(\mathrm{b})$ and $\mathrm{e}(\mathrm{b})$ denote respectively transfer, rent, cost-target and exort level that accrues to $a$..rm that reports $b$ when the other ..rm reports $b^{0}$. Let ${ }^{-}=\left(^{-} ;-9\right.$ be the vector of true types.

Lemma A.1. A mechanism is truthful only if:

$$
t\left(^{-}\right)={ }_{-}^{-\left(^{-}\right)} \tilde{A} q e(x ;-9) d x+U\left(^{-}\left({ }^{-}\right) ;-9+\tilde{A}\left(e^{-}\right)\right) 8^{-} 2 A_{1}^{2}\left[A_{2}^{2} .\right.
$$

Proof. By de. nition $V\left(b ;{ }^{-}\right)=E-0\left[t(b ;-9] ; E-0\left[\tilde{A}\left(\left(^{-} ; C\left(b ;{ }^{-} 9\right)\right]\right.\right.\right.$. E-o[t( $\left.\phi\right]$ is expected transfer and $E-0[\tilde{A}(e(\Phi)]$ is expected disutility of exort, conditional on the other ..rm telling the truth and on ${ }^{-}$. $E_{-0}^{-}\left[\mathbb{\Phi}\right.$ is independent of ${ }^{-}$because the conditional distribution $f\left({ }^{-} g^{-}\right)=g\left(^{-} g\right.$ is independent of ${ }^{-}$. Thus $V\left(b ;{ }^{-}\right)=$ $V(b)+E-0\left[\tilde{A}\left(e\left(b_{;}{ }^{-9}\right)\right] ; \quad E-0\left[\tilde{A} q^{-} ; C\left(b ;{ }^{-9}\right)\right]\right.$. Use (3.4) and dixerentiate to obtain:

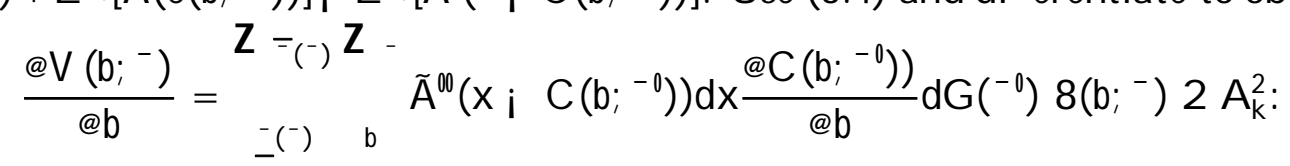

We see that $@\left(b{ }^{-}\right)=@ b=0$ is met at the optimum $b={ }^{-}$for all realizations of ${ }^{-} 0$, hence indirect utility satis.es @U $\left.\left(^{-}\right)=@=i \tilde{A} 9\left(e^{-}\right)\right)$. Use this and $U\left(^{-}\right)=$ $\mathrm{t}\left(\left(^{-}\right)\right.$i $\left.\tilde{\mathrm{A}}\left(\mathrm{e}^{-}\right)\right)$to obtain (A.1).

Lemma A.2. The side contract $\$=f^{\circ} ;{ }^{\prime} g$ de. ned below is feasible under every truthful mechanism.

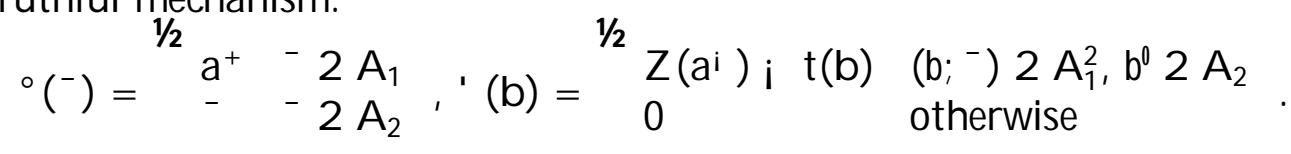


Proof. Feasibility of $\$$ is obvious for ${ }^{-} 2 A_{2}$ because there is no collusion in that case. Suppose therefore that ${ }^{-} 2 A_{1} \cdot Z\left(b_{;}{ }^{-}\right)=Z\left(a^{i}\right)$ i $\tilde{A}\left(\left(^{-}\right.\right.$i $\left.C\left(b ; a^{+}\right)\right) \cdot Z\left(\left(^{-}\right)\right.$ $8\left(b ; ;^{-}\right) 2 A_{1}^{2}$. The inequality follows from $\left.Z\left(^{-}\right)=i \tilde{A} q^{-} ; C\left(a^{+} ; a^{+}\right)\right)<0$ and $\tilde{A}, 0 . Z\left(b ; i^{-}\right)=t\left(b ; a^{+}\right)$i $\tilde{A}\left({ }^{-} i C\left(b ; a^{+}\right)\right) 8\left(b ; i^{-}\right) 2 A_{2} \notin A_{1}$. Use $(A .1)$ and dixerentiate to get:

$$
\frac{@ Z\left(b ; ;^{-}\right)}{@ b}={ }_{b} \tilde{A}^{0}\left(x_{i} C\left(b ; a^{+}\right)\right) d x \frac{@\left(b ; a^{+}\right)}{@ b} \cdot 08\left(b ;{ }^{-}\right) 2 A_{2} \neq A_{1} .
$$

The inequality is implied by monotonicity of $C$ in $b$ and $b>{ }^{-}$.

\section{A.1. Individual regulation of ..rms}

Rents are minimized if $U\left(a^{i}\right)=U\left(a^{+} ; a^{i}\right) . U\left(a^{+} ; a^{i}\right)=U\left(a^{+}\right)+\tilde{A}\left(e\left(a^{+}\right)\right) i$ $\tilde{A}\left(a^{i}\right.$ i $C\left(a^{+}\right)$). Substitute this into (3.8) to get an expression for $U\left(^{-}\right)$that depends entirely on exort and $U\left(^{-}\right) . U(\Phi$ is decreasing, hence (3.10) is met if $U\left(^{-}\right)=0$. Substitute the new expression for $U^{(-)}$into (3.7) and do an integration by parts to get:

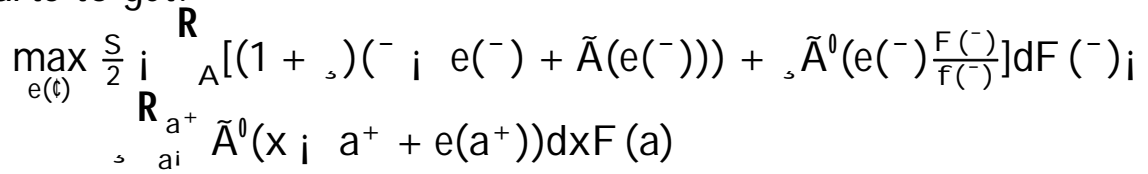

$$
\begin{aligned}
& \text { s.t. } \left.\mathrm{C}^{-}{ }^{-}\right) \text {increasing on } A \text {. }
\end{aligned}
$$

Denote expected welfare (A.3) by $W^{s}$. The last term in (A.3) enters due to non-convexity of $A$. Pointwise maximization of $W^{s}$ violates the monotonicity requirement (A.4). Therefore there is some bunching at the optimum. ${ }^{-s}$ is found by substituting optimal levels of exort (3.11) and (3.12) back into $W^{s}$ and dixerentiating wrt ${ }^{-s}$. This renders a ...rst order condition for optimal bunching:

$$
\begin{aligned}
& \text {, } \mathrm{a}_{\mathrm{a}^{+}} \tilde{A} \tilde{A}\left(x ; C^{s}\left(^{-s}\right)\right) d x F(a), \quad{ }_{a^{+}}\left[(1+,)\left(1 ; i \tilde{A} q e^{s}(-)\right)\right) i \\
& \text { i. } \left.\frac{\bar{F}^{-}\left({ }^{-}\right)}{f\left(\left(^{-}\right)\right.} \tilde{A}\left(\mathrm{e}^{s}\left({ }^{-}\right)\right)\right] \mathrm{dF}\left(^{-}\right) \text {. }
\end{aligned}
$$

$\mathrm{W}^{\mathrm{s}}$ is concave at the interior solution. Note that ${ }^{-\mathrm{s}}>\mathrm{a}^{+}$unless $\mathrm{a}^{+}=\mathrm{a}^{\mathrm{i}}$, in which case there is no bunching. The equality is strict when ${ }^{-s}<^{-}$, but the possibility of a corner solution at ${ }^{2}$ is not ruled out. 


\section{A.2. Proof of proposition 5.2}

Consider the regulatory contract $D^{\mathrm{yc}}=\mathrm{ft}^{\mathrm{yc}} ; C^{\mathrm{yc}} \mathrm{g}$ with cost target $C^{\mathrm{yc}}(\mathrm{b})=$ $C^{y c}(b)=b_{i} e^{y c}(b)$ for all $b 2 A^{2}$ and with transfers:

$$
\mathrm{t}^{\mathrm{yc}}(\mathrm{b})=\begin{array}{ll}
<r^{\mathrm{yc}}(b) & \text { b } 2 A_{k}^{2}, k=1 ; 2 \\
r^{\mathrm{yc}}(b)+r & b 2 A_{1} ; b^{0} 2 A_{2} \\
\tilde{A}^{0}\left(a^{i} ; C^{y c}(b)\right) ; & b 2 A_{2} ; b^{0} 2 A_{1}
\end{array},
$$

where

$$
\left.r^{y c}(b), \quad{ }_{b}^{Z}{ }^{-(b)} \tilde{A} q e^{y c}(x)\right) d x+\tilde{A}\left(e^{y c}(b)\right) ;
$$

$r, r^{y c}\left(a^{+}\right) ; \tilde{A}\left(a^{i} ; C^{y c}\left(a^{+}\right)\right)$and $\pm>0$ is a small number. It is shown below that truth-telling is the unique BNE when the regulator proposes $D^{\mathrm{yc}}$. This implies that both ..rms meet the cost target $\mathrm{Cyc}^{\mathrm{yc}}\left(^{-}\right)={ }^{-}{ }^{-} \mathrm{e}^{\mathrm{yc}}\left({ }^{-}\right)$, hence the social choice function $e^{y c}(\Phi$ is implemented as a unique BNE.

First, strict monotonicity of $C^{y c}$ is proved: $C^{y c}\left({ }^{-}\right)=1_{i} \underline{e}^{y c}\left(^{-}\right)>0$ on ${ }^{-} 2$ $\left.\left[{ }^{-}\right) ;^{-}\left({ }^{-}\right)\right]$by $\underline{e}^{\mathrm{yc}}\left({ }^{-}\right) \cdot 0 . C^{y c}$ is globally strictly increasing if $\mathrm{C}^{\mathrm{yc}}\left(\mathrm{a}^{\mathrm{i}}\right)<\mathrm{C}^{\mathrm{yc}}\left(\mathrm{a}^{+}\right)$. This is equivalent to $a^{+} i a^{i}>\tilde{A}^{9}{ }^{1}(1)$ i $e^{y c}\left(a^{i}\right)$ since $\left.\tilde{A} q e^{y c}\left(a^{+}\right)\right)=1 . a^{+} i a^{i}$, $\tilde{A}^{9}{ }^{1}(1)$ holds for all ${ }^{\circledR}$ that satisfy (2.4).

Denote by $4 \mathrm{U}$ a ..rm of type ${ }^{-}$'s net bene.t of truthfully reporting - over $b$ when the other ..rm reports $b^{0}$. By invoking (A.6) and (A .7), it is straightforward to show that

$$
4 U={ }_{-c_{c^{y c}(x)} Z_{c^{y c}(b)}}^{A^{a}(x ; y) d y d x} 8\left(b ;^{-}\right) 2 A_{1} £ A f A_{1},
$$

where $b=\left(b ; b 9\right.$. Strict monotonicity of $C^{y c}$ implies that (A .8) is strictly positive unless $b={ }^{-}$, in which case $4 U=0$. Next,

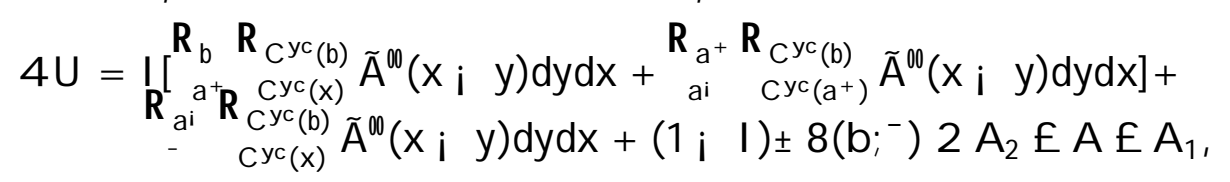

where $I$ is an indicator function that takes on the value 1 for $b^{0} 2 A_{2}$ and zero otherwise. (A .9) is strictly positive for all ${ }^{-}<a^{i}$ and non-negative for ${ }^{-}=a^{i}$. 
Thus, truth-telling is a strictly dominating strategy for all ${ }^{-}<a^{i}$ and a weakly dominating strategy for ${ }^{-}=a^{i}$. In equilibrium $b^{0}={ }^{-0}$ for all ${ }^{-}<a^{i}$, hence $\mathrm{I}=0$ for almost every $\mathrm{b}$. The ...rm's expected loss of reporting b2 $A_{2}$ is therefore $\pm>0$ for $^{-}=a^{i}$. Hence, truth-telling is the unique BNE for all ${ }^{-} 2 A_{1}$.

Consider next the case with ${ }^{-} 2 \mathrm{~A}_{2}$. Proceed in a similar fashion as before to obtain:

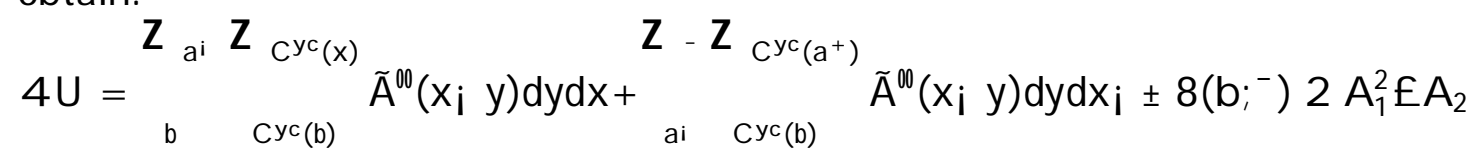

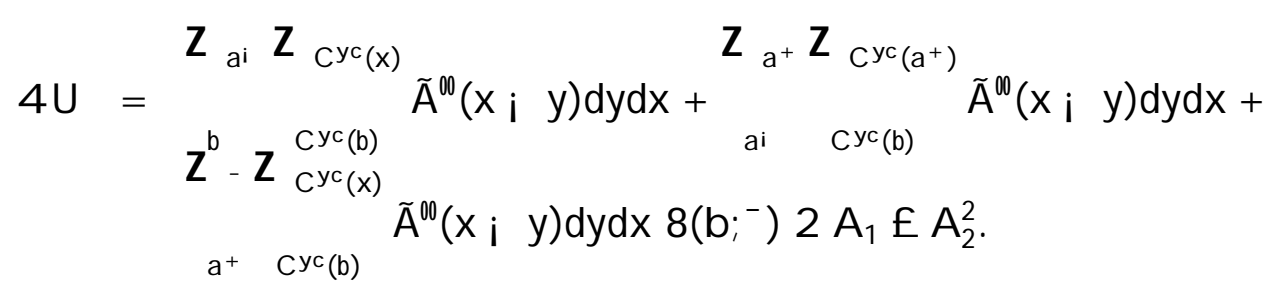

The..rst expression is positive for \pm su Thus, a ..rm with ${ }^{-} 2 A_{2}$ strictly loses by reporting b $2 A_{1}$ irrespective of what the other ..rm reports. Therefore both ..rms report b $2 A_{2}$ in equilibrium. We can derive the same expression as in (A .8) to show that truth-telling is the unique best-reply for ${ }^{-} 2 A_{2}$ under the constraint $b^{0} 2 A_{2}$. Hence, truth-telling is the unique $B N E$ also for all ${ }^{-} 2 A_{2}$.

\section{A.3. Collusion-proof regulation}

The regulator maximizes (5.1) subject to (5.2)-(5.4). From section 3 we know that (5.2)-(5.3) can be replaced by (3.4)-(3.6), $\vee\left(a^{i}\right), 0$ and $V\left(^{(}\right)$, 0 . Set $V\left(^{-}\right)=0$ and eliminate (3.5) by setting $t(b)=0$ 8b $2 A_{k}\left[A_{k}^{c}, k=1 ; 2\right.$. The remaining constraints are now (3.4), (3.6), (5.4) and $V\left(a^{i}\right), 0$. The collusionproof mechanism is truthful. This implies that the side contract $\$$ de. ned by (A.2) is feasible (lemma A .2). Thus a necessary condition for (5.4) to hold is:

$$
{ }^{Z_{a i}} V\left(( ^ { - } ) d F \left(\left(^{-}\right)={ }_{-}^{Z_{a i}}\left(t^{+} ; \tilde{A}\left(^{-} ; C^{+}\right)\right) d F\left(\left(^{-}\right)\right. \text {, }\right.\right.
$$


with $\mathrm{t}^{+}, \mathrm{t}\left(\mathrm{a}^{+} ; \mathrm{a}^{+}\right), \mathrm{e}^{+}, \mathrm{e}\left(\mathrm{a}^{+} ; \mathrm{a}^{+}\right)$and $\mathrm{C}^{+}=\mathrm{a}^{+} \mathrm{i} \mathrm{e}^{+} .(\mathrm{A} .10)$ states that total expected rents are identical under the truthful side contract and under the collusive side contracts \$. A ssume for the moment that (A.10) is also suф cient and, consequently, strictly binding. Under a truthful mechanism the transfer $\left.\mathrm{t}^{-}{ }^{-}\right)$ is de..ned by (A.1). Use this to derive an expression for $\mathrm{t}^{+}$, substitute it into the binding constraint (A.10) and do an integration by parts to obtain:

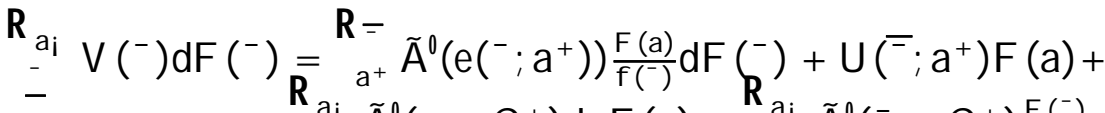

$$
\begin{aligned}
& \left.\left.+{ }_{-}^{R_{a i}} \tilde{A} q x_{i} C^{+}\right) d x F(a)+{ }_{-}^{R_{a i}} \tilde{A} q^{-} ; C^{+}\right) \frac{\left.F()^{-}\right)}{\left.f()^{-}\right)} d F\left(\left(^{-}\right)\right. \text {. }
\end{aligned}
$$

If (A.10) is the binding collusive incentive compatibility constraint, expected rents to each ..rm is equal to (A.11) plus

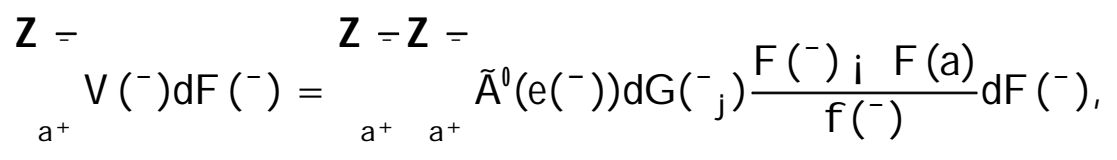

where I have used (3.4) and $\left.V^{(}\right)=0$ to obtain the expression in (A.12). Clearly, rents to the ..rm are independent of the type of the other ..rm ${ }^{-}$, hence $\left.\mathrm{e}^{-}\right)=$ $\left.\mathrm{e}^{-}\right)$. In particular, $\mathrm{U}\left({ }^{-} ; \mathrm{a}^{+}\right)=\mathrm{U}\left(^{-}\right)=\mathrm{V}\left(^{-}\right)=0$ and $\left.\left.\mathrm{e}^{-} ; \mathrm{a}^{+}\right)=\mathrm{e}\left(^{-}\right)=\mathrm{e}^{-}\right)$.

I now verify that (A.10) is suф cient for (5.4) to hold. Firms receive no rents if they deliver incompatible cost reports. Thus colluding ..rms always deliver compatible cost reports in equilibrium. By (A.10), (3.4), independence $\left(\mathrm{e}^{-}\right)=$ $\left.\mathrm{e}^{-}\right)$) and monotonicity of $C$ in ${ }^{-}$, we have ${ }^{\circ}\left({ }^{-}\right)={ }^{-} 8^{-} 2 A_{1}$ and ${ }^{\circ}\left({ }^{-}\right)=a^{i}$ $8^{-} 2 A_{2}$ or ${ }^{\circ}\left({ }^{-}\right)={ }^{-} 8^{-} 2 A_{2}$ in the optimal side contract. ${ }^{\circ}\left({ }^{-}\right)=$ai cannot be optimal because $U\left(a^{i} ;^{-}\right)=\tilde{A}\left(e\left(a^{i}\right)\right)$ i $\tilde{A}\left({ }^{-}\right.$i $\left.C\left(a^{i}\right)\right)<0 \cdot U\left({ }^{-}\right)$. The .rst inequality follows from ${ }^{-}>a^{i}$, the second from individual rationality. Thus (A.10) is suc cient for (5.4) to hold.

A dd (A.11) and (A.12) and simplify to get expected ..rm rents under collusionproof regulation:

$$
\begin{aligned}
& \left.\left.{ }_{A}^{R} U\left(^{-}\right) d F\left(^{-}\right)={ }_{R^{-}}^{R} \tilde{A} q e^{-}\right)\right) \frac{F\left(\left(^{-}\right)\right.}{f\left(\left(^{-}\right)\right.} d F\left(\left(^{-}\right)+R_{a^{i}} \tilde{A} q\left(x ; \quad C\left(a^{+}\right)\right) d x F(a)\right. \\
& \left.+\stackrel{-}{R_{a i}} \tilde{A} q^{-} \text {i } C\left(a^{+}\right)\right) \frac{F\left(\left(^{-}\right)\right.}{f\left(\left(^{-}\right)\right.} d F\left(^{-}\right) \text {. }
\end{aligned}
$$


Substitute (A.13) into (5.1) to obtain (5.6). The remaining constraints are (3.6) and $\mathrm{V}\left(\mathrm{a}^{\mathrm{i}}\right), 0$. (3.6) and $\left.\mathrm{C}^{-}\right)=\mathrm{C}\left(^{-}\right)$imply (5.7). Use $\left.\left.\mathrm{e}^{-}\right)=\mathrm{e}^{-}\right)$and do an integration by parts on (3.4) to obtain:

$$
Z_{-}^{Z_{i}} V\left(^{-}\right) d F\left(\left(^{-}\right)={ }_{-}^{Z_{a i}} \tilde{A} q\left(e\left(^{-}\right)\right) \frac{F\left(\left(^{-}\right)\right.}{f\left(^{-}\right)} d F\left(\left(^{-}\right)+F(a) V\left(a^{i}\right) .\right.\right.
$$

Subtract this expression from (A.10), use that ..rms are identical ex ante, and rearrange terms to get:

$$
\left.F(a) V\left(a^{i}\right)={ }_{-}^{Z_{a i}}\left[t^{+} \text {i } \tilde{A}\left({ }^{-} i C^{+}\right) \text {i } \tilde{A} q\left(e^{-}\right)\right) \frac{F\left(^{-}\right)}{f\left(^{-}\right)}\right] d F\left(^{-}\right) .
$$

$\mathrm{V}\left(\mathrm{a}^{\mathrm{i}}\right), 0$ is equivalent to (5.8).

In order to derive the optimal level of bunching under collusion-proof regulation, insert (5.10)-(5.12) into the Lagrangian (5.9) and dixerentiate wrt. ${ }^{-c p}$ to get the FOC:

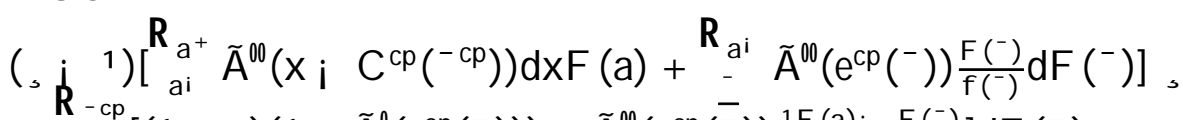

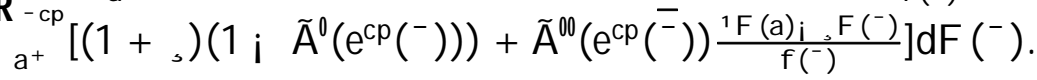

The LHS is marginal rent-extraction, the RHS is marginal welfare loss from distortion of elc ciency.

\section{A.4. Proof of proposition 5.4}

$\mathrm{e}^{\mathrm{cp}}\left(^{-}\right)<\mathrm{e}^{\mathrm{yc}}\left(^{-}\right) 8^{-} 2\left[\mathrm{a}^{+} ;^{-}\right]$: Compare equations (3.13) and (5.11). Optimal exort is decreasing in the hazard rate by the assumptions on $\tilde{A}$. Thus $\mathrm{e}^{\mathrm{cp}}\left(^{-}\right)<\mathrm{e}^{\mathrm{yc}}\left(^{-}\right)$ $8^{-} 2\left[^{-{ }^{-c p}} ;^{-}\right]$since $F\left(^{-}\right)=\left(^{-}\right)<\left(F\left(^{-}\right)\right.$i $\left.\left.F(a)\right)=f^{-}\right)$. Further, $e^{c p}\left({ }^{-}\right)=e^{c p}\left({ }^{-c p}\right)+$

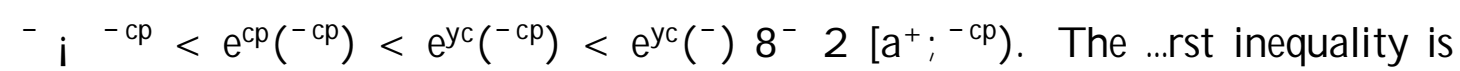
obvious, the second follows from the ..rst part of this proof, the third from the assumption that $\mathrm{F} f$ is increasing in ${ }^{-}$and the fact that e is decreasing in $\mathrm{F} f$. For later reference, observe that $\tilde{A}^{\oplus}>0$ and $\mathrm{e}^{\mathrm{cp}}\left(^{-}\right)<\mathrm{e}^{\mathrm{yc}}\left(^{-}\right)$imply

$$
\left.V^{\mathrm{CP}}\left({ }^{-}\right)={ }_{-}^{Z-} \tilde{A} q\left(e^{\mathrm{cp}}(\mathrm{x})\right) \mathrm{dx}<{ }_{-}^{Z-} \tilde{A} q \mathrm{e}^{\mathrm{yc}}(\mathrm{x})\right) \mathrm{dx}=\mathrm{V}^{\mathrm{yc}}\left({ }^{-}\right) 8^{-} 2\left[\mathrm{a}^{+} ;{ }^{-}\right) .
$$


$\mathrm{e}^{\mathrm{CP}}\left(^{-}\right)>\mathrm{e}^{\mathrm{yc}\left(^{-}\right)} 8^{-} 2\left(_{-}^{-} ; \mathrm{a}^{\mathrm{i}}\right]$ : Second-best regulation is non-collusion-proof, so the regulator must give up rents to ..rms to prevent collusion, i.e. $E-\left[V^{c p}\left({ }^{-}\right)\right]>$ $\mathrm{E}-\left[\mathrm{V}^{\mathrm{YC}}\left(^{-}\right)\right]$in equilibrium. Observe from equation (5.10) that $\mathrm{e}^{\mathrm{cp}}\left(^{-}\right)$is decreasing in ${ }^{1}$. Thus for every ${ }^{-} 2\left(^{-} ; a^{i}\right] ; e^{c p}\left({ }^{-}\right) R e^{y c}\left(^{-}\right),{ }^{1} Q,{ }^{1}$, is impossible since it would imply $\mathrm{E}-\left[\mathrm{V}^{\mathrm{cP}}\left({ }^{-}\right)\right]<\mathrm{E}-\left[\mathrm{V}^{\mathrm{yc}}\left(^{-}\right)\right]$by $(\mathrm{A} .15)$ and

$$
V^{c P}\left({ }^{-}\right)={ }_{-}^{Z_{a i}} \tilde{A} q\left(e^{c p}(x)\right) d x \cdot{ }_{-}^{Z_{a i}} \tilde{A} q\left(e^{y c}(x)\right) d x=V^{y c}\left(^{-}\right) 8^{-} 2\left[{ }^{-} ; a^{i}\right] .
$$




\section{SEMINAR PAPER SERIES}

The Series was initiated in 1971. For a complete list of Seminar Papers, please contact the Institute.

616. Assar Lindbeck:

617. Assar Lindbeck:

618. Javier Ortega:

619. Joakim Persson and Bo Malmberg:

620. Assar Lindbeck and Dennis J. Snower:

621. Paul Söderlind and Lars E.O. Svensson:

$\underline{1997}$

622. Assar Lindbeck:

623. John Hassler and José Vicente Rodriguez Mora:

624. Nils-Petter Lagerlöf:

625. Lars E.O. Svensson:

626. James E. Anderson:

627. Mårten Blix:

628. Assar Lindbeck and Dennis J. Snower:

629. Etienne Wasmer:

630. Torsten Persson and
The West European Employment Problem. 31 pp.

Full Employment and the Welfare State. 22 pp.

How (Good) Immigration Is: A Matching Analysis. $30 \mathrm{pp}$.

Human Capital, Demographics and Growth Across the US States 1920-1990. 21 pp.

Centralized Bargaining, Multi-Tasking, and Work Incentives. $43 \mathrm{pp}$.

New Techniques to Extract Market Expectations from Financial Instruments. $47 \mathrm{pp}$

Incentives and Social Norms in Household Behavior. $12 \mathrm{pp}$.

Employment Turnover and Unemployment Insurance. $36 \mathrm{pp}$.

Strategic Saving and Non-Negative Gifts. 20 pp.

Inflation Targeting: Some Extensions. 43 pp.

Revenue Neutral Trade Reform with Many Households, Quotas and Tariffs. 36 pp.

Rational Expectations in a VAR with Markov Switching. 37 pp.

The Division of Labor Within Firms. 12 pp.

Can Labour Supply Explain the Rise in Unemployment and Inter-Group Wage Inequality in the OECD? $64 \mathrm{pp}$.

Political Economics and Macroeconomic Policy.100 pp. 
Guido Tabellini:

631. John Hassler and Assar Lindbeck:

632. Michael Woodford:

633. Torsten Persson, Gérard Roland and Guido Tabellini:

634. Johan Stennek:

$\underline{1998}$

635. John Hassler and

José V. Rodríguez Mora:

636. Jon Faust and

Lars E. O. Svensson:

637. Glenn D. Rudebusch and Lars E. O. Svensson:

638. Lars E. O. Svensson:

639. Lars Calmfors:

640. Assar Lindbeck:

641. Donald Brash:

642. Claes Berg and Lars Jonung:

643. Jürgen von Hagen:

644. Bennett T. McCallum and Edward Nelson:

645. Assar Lindbeck:

646. Lars E.O. Svensson:
Intergenerational Risk Sharing, Stability and Optimality of Alternative Pension Systems. 38 pp.

Doing Without Money: Controlling Inflation in a Post-Monetary World. $62 \mathrm{pp}$.

Comparative Politics and Public Finance. 55 pp.

Coordination in Oligopoly. $14 \mathrm{pp}$.

IQ, Social Mobility and Growth. 34 pp.

Transparency and Credibility: Monetary Policy with Unobservable Goals. 40 pp.

Policy Rules for Inflation Targeting. 51 pp.

Open-Economy Inflation Targeting. 51 pp.

Unemployment, Labour-Market Reform and Monetary Union. $35 \mathrm{pp}$

Swedish Lessons for Post-Socialist Countries. 37 pp.

Inflation Targeting in New Zealand: Experience and Practice. $11 \mathrm{pp}$.

Pioneering Price Level Targeting: The Swedish

Experience 1931-1937. 50 pp.

Money Growth Targeting. 34 pp.

Nominal Income Targeting in an Open-Economy Optimizing Model. 48 pp.

Swedish Lessons for Post-Socialist Countries. $42 \mathrm{pp}$.

Inflation Targeting as a Monetary Policy Rule. $51 \mathrm{pp}$. 
647. Jonas Agell and Mats Persson:

648. Frederic S. Mishkin:

649. John B. Taylor:

650. Christopher J. Erceg, Dale W. Henderson and Andrew T. Levin:

651. Etienne Wasmer:

652. Daron Acemoglu and Fabrizio Zilibotti:

653. Argia Sbordone:

654. Martin Flodén and Jesper Lindé:

655. Thomas P. Tangerås:

656. Peter Svedberg:

657. Lars Calmfors:

658. Torsten Persson and Guido Tabellini:

659. Lars Calmfors:

660. Daron Acemoglu and Fabrizio Zilibotti:

661. Ramon Marimon and Fabrizio Zilibotti:

662. Yves Zenou:
Tax Arbitrage and Labor Supply. 35 pp.

International Experiences With Different Monetary Policy Regimes. 47 pp.

The Robustness and Efficiency of Monetary Policy Rules as Guidelines for Interest Rate Setting by The European Central Bank. 39 pp.

Tradeoffs Between Inflation and Output-Gap Variances in an Optimizing-Agent Model. 43 pp.

Labor Supply Dynamics, Unemployment and Human Capital Investments. 36 pp.

Information Accumulation in Development. 43 pp.

Prices and Unit Labor Costs: A New Test of Price Stickiness. 33 pp.

Idiosyncratic Risk in the U.S. and Sweden: Is there a Role for Government Insurance? 30 pp.

On the Role of Public Opinion Polls in Political Competition. 36 pp.

841 Million Undernourished? On the Tyranny of Deriving a Number. 39 pp.

Macroeconomic Policy, Wage Setting and Employment - What Difference Does the EMU Make? 52 pp.

The Size and Scope of Government: Comparative Politics with Rational Politicians. 47 pp.

Monetary Union and Precautionary Labour-Market Reform. $10 \mathrm{pp}$.

Productivity Differences. 48 pp.

Unemployment vs. Mismatch of Talents: Reconsidering Unemployment Benefits. 35 pp.

Urban Unemployment and City Formation. Theory and Policy Implications. 35 pp. 
663. Stefan Palmqvist:

664. Kjetil Storesletten:

665: John Hassler,

José V. Rodríguez Mora, Kjetil Storesletten and Fabrizio Zilibotti:

$\underline{1999}$

666. Michael Woodford:

667. Lars E.O. Svensson:

668. Assar Lindbeck:

669. Lars E.O. Svensson:

670. Assar Lindbeck and Solveig Wikström:

671. Lars E.O. Svensson:

672. Glenn Rudebusch and Lars E.O. Svensson:

673. Lars Svensson:

674. Thomas P. Tangerås:
Why Central Banks Announce Their Objectives: Monetary Policy with Discretionary Signalling. 22 pp.

Sustaining Fiscal Policy Through Immigration. 41 pp.

Equilibrium Unemployment Insurance. 56 pp.
Optimal Monetary Policy Inertia. 112 pp.

Monetary Policy Issues for the Eurosystem. 54 pp.

The Price in Economic Sciences In Memory of Alfred Nobel 1969-1998. 28 pp.

The Equilibrium Degree of Transparency and Control in Monetary Policy. 25 pp.

The ICT Revolution in Consumer Product Markets. 23 pp.

Does the $P^{*}$ Model Provide Any Rationale for Monetary Targeting? $14 \mathrm{pp}$.

Eurosystem Monetary Targeting: Lessons from U.S. Data. 29 pp.

Price Stability as a Target for Monetary Policy Defining and Maintaining Price Stability. 50 pp.

Collusion-Proof Yardstick Competition. 33 pp.

ISSN 0347-8769

Stockholm, 1999

Institute for International Economic Studies 